\title{
Pulmonary function after laparoscopic cholecystectomy in the elderly
}

\author{
A. Milheiro, F. CASTRO SOUSA, L. OLIVEIRA* and M. JOÃO MATOS* \\ Departments of Surgery and *Pneumology, University of Coimbra Hospital, Coimbra, Portugal \\ Correspondence to: Dr A. Milheiro, Rua Condessa do Ameal 49-2 ${ }^{\circ}, 3030$ Coimbra, Portugal
}

The results of laparoscopic cholecystectomy in a group of 52 patients older than 69 years (group 1) were compared with the results of the same operation in a group of 338 younger patients (group 2). In group 1, 23 per cent of patients had acute cholecystitis and 13 per cent were operated on after an episode of acute pancreatitis. In group 2, 8 per cent of patients had acute cholecystitis and 4 per cent were operated on after acute pancreatitis. Pulmonary function was assessed prospectively before operation, $24 \mathrm{~h}$ after surgery and on the seventh day after operation, in 20 patients in group 1 and 30 in group 2 . In group 1 there was one death ( 2 per cent); the morbidity rate was 14 per cent and conversion to laparotomy was required in 15 per cent. In group 2 there were no deaths, the morbidity rate was 11 per cent and the conversion rate 4 per cent. No significant differences were found between the two groups in mortality and morbidity rates. Preoperative values of forced vital capacity (FVC) and forced expiratory volume in $1 \mathrm{~s}\left(\mathrm{FEV}_{1}\right)$ were significantly lower in group 1 than in group $2(P<0 \cdot 05)$; the values of $\mathrm{FVC}, \mathrm{FEV}_{1}$ and forced expiratory flow at 50 per cent $24 \mathrm{~h}$ after surgery were less depressed in group $1(P<0.01)$ and also recovered more quickly in these patients 7 days after operation. Laparoscopic cholecystectomy gives excellent results in geriatric patients and can be recommended as the treatment of choice for symptomatic cholelithiasis in the elderly.
The continuing ageing of the Portuguese population has led to a significant rise in the number of patients submitted to operations such as cholecystectomy. The introduction of the laparoscopic approach, with its recognized benefits of less discomfort, shortened hospital stay and rapid return to normal activity, represents a new challenge and it is necessary to determine whether these benefits are also experienced by elderly patients, who are generally considered to have diminished cardiopulmonary reserve.

The increase in intra-abdominal pressure during pneumoperitoneum causes a decrease in lung compliance and a rise in peak inspiratory pressure. Atelectasis, reduced functional residual capacity, ventilation-perfusion mismatch and pulmonary shunting contribute to a decrease in arterial oxygenation!. Moreover, high insufflation pressures tend to compress the major abdominal veins (particularly the inferior vena cava), which compromises venous return and leads to a drop in preload and cardiac output in some patients ${ }^{2}$. When hypercapnia is allowed to develop, it may stimulate the sympathetic nervous system and thus increase blood pressure, heart rate and the risk of dysrhythmia. Although these effects are usually well tolerated in healthy people, they can be more serious in patients with impaired cardiac function, restrictive lung disease or intravascular volume depletion $^{3}$.

The aim of this study was to present the results of laparoscopic cholecystectomy in patients older than 69 years and to compare results with those obtained in the treatment of cholelithiasis in younger patients. The study also reports a prospective assessment of pulmonary function after laparoscopic cholecystectomy in both age groups.

\section{Patients and methods}

Between January 1992 and December 1994, 390 consecutive patients underwent laparoscopic cholecystectomy. Fifty-two (13

Paper accepted 19 November 1995 per cent) were 70 or more years old (group 1) and 338 were younger (group 2).

In group 1 the 52 patients ( 36 women) were of mean age 74 (range 70-90) years; 39 patients were classified as American Society of Anesthesiologists (ASA) grade I, ten as ASA II and three as ASA III. Mean(s.d.) weight and height were $68(15) \mathrm{kg}$ and $1.56(0.09) \mathrm{m}$. Forty-one patients were found to have several stones in the gallbladder, nine had a single stone and two gallbladder adenoma. Twelve patients $(23$ per cent $)$ were operated on for acute cholecystitis and seven (13 per cent) for acute pancreatitis of biliary origin. Three patients had had a previous episode of jaundice and 11 previous abdominal surgery. Preoperative endoscopic retrograde cholangiopancreatography (ERCP) was performed in five patients and demonstrated stones in three. Pulmonary function was assessed prospectively in 20 consecutive patients before operation, $24 \mathrm{~h}$ after surgery and on the seventh day after operation. Forced vital capacity (FVC), forced expiratory volume in $1 \mathrm{~s}\left(\mathrm{FEV}_{1}\right)$ and forced expiratory flow at 50 per cent $\left(\mathrm{FEF}_{50}\right)$ were measured. No patient was excluded from the study.

In group 2 the 338 patients ( 244 women) were of mean(s.d.) age $49.5(11)$ years; 278 patients were classified as ASA grade I, 51 as ASA II and nine as ASA III. Mean(s.d.) weight and height were $69(12) \mathrm{kg}$ and $1 \cdot 59(0 \cdot 40) \mathrm{m}$. Some 249 patients were found to have several stones in the gallbladder, 70 had a single stone and 19 had gallbladder adenoma. Twenty-six patients $(8$ per cent) were operated on for acute cholecystitis and 13 (4 per cent) for acute biliary pancreatitis. Seven patients had a previous history of jaundice and 106 had undergone previous abdominal surgery. ERCP was performed on two patients and intravenous cholangiography on two more; nevertheless none of these tests showed stones in the common bile duct (CBD). Pulmonary function testing as described above was performed prospectively in 30 consecutive patients before operation, $24 \mathrm{~h}$ after surgery and on day 7. Again no patient was excluded from the study.

An operative cholangiogram was obtained in all cases of acute cholecystitis and acute pancreatitis, and in other patients at risk of common duct stones.

\section{Statistical analysis}

For statistical evaluation Student's $t$ test and contingency table analysis were used in the program StatView $512+$, version 1.01 (Abacus Concepts; Brainpower, Calabasas, California, USA), run on a personal computer. $P<0.05$ was considered significant. 


\section{Results}

One patient in group 1 died (mortality rate 2 per cent). The patient, in whom conversion to laparotomy was required to repair a $\mathrm{CBD}$ injury, died from mesenteric infarction following a large haematoma of the transverse mesocolon. This patient suffered from von Willebrand's disease. Complications in group 1 consisted of loss of gallstones in the abdominal cavity $(n=3)$, subcutaneous emphysema $(n=2)$, bladder infection (in one patient with a Foley catheter waiting for urological surgery) and pneumonia $(n=1)$ (total seven of 51 or 14 per cent). Conversion to laparotomy was required in eight patients (15 per cent) and was due to distorted anatomy $(n=7)$ and CBD injury $(n=1)$. A drain was left in three patients. The mean(s.d.) operating time was 76(29) min and median hospital stay after surgery was 3 days. Mean(s.d.) values of FVC, $\mathrm{FEV}_{1}$ and $\mathrm{FEF}_{50}$ before operation were $2 \cdot 3(0 \cdot 78)$ litres, $2 \cdot 0(0 \cdot 7)$ litres and $3 \cdot 2(1 \cdot 4) \mathrm{l} / \mathrm{s}$ respectively. The changes from preoperative values are shown in Table 1.

There were no deaths in group 2. Complications were loss of gallstones in the abdominal cavity $(n=18)$, subcutaneous emphysema $(n=6)$, wound infection $(n=4)$, bile leakage requiring laparotomy $(n=2)$, perforation of the diaphragm $(n=2)$, bleeding from a trocar site $(n=2)$, intra-abdominal abscess (infected haematoma) $(n=1)$, stenosis of the main bile duct (further laparotomy for repair) $(n=1)$ and hepatic laceration $(n=1)$ (total 37 of 338 or 11 per cent). In 13 patients a drain was left for $24 \mathrm{~h}$ and 14 procedures ( 4 per cent) required conversion to laparotomy, due to distorted anatomy $(n=12)$, haemorrhage (posterior branch of the cystic artery) $(n=1)$, and malfunction of the optical system $(n=1)$. The mean(s.d.) operating time was $73(36)$ min and median hospital stay after surgery was 2.5 days. The mean(s.d.) values of FVC, FEV 1 and $\mathrm{FEF}_{50}$ before operation were $3 \cdot 5(0 \cdot 9)$ litres, $2 \cdot 8(0 \cdot 8)$ litres and $3 \cdot 7(1 \cdot 3) 1 / \mathrm{s}$ respectively. The changes from preoperative values are shown in Table 1.

No significant differences were found between the two groups in sex distribution, weight, height, ASA grade, haemoglobin level, haematocrit, total plasma bilirubin, plasma alanine aminotransferase, mortality, morbidity, operating time and hospital stay. Apart from age significant differences were found in the mean(s.d.) levels of alkaline phosphatase $(109(82)$ units/l in group 1 versus $73(43)$ units/1 in group 2); the incidence of acute cholecystitis $(P=0.0001)$ and of acute pancreatitis $(P=0.003)$ were significantly greater in group 1 and there

Table 1 Postoperative pulmonary function

\begin{tabular}{rclc}
\hline & Group 1 & Group 2 & $P$ \\
\hline FVC & & & \\
Day 1 & $90(12)$ & $72(19)$ & $<0.01$ \\
Day 7 & $102(9)$ & $97(8)$ & n.s. \\
FEV & & & \\
Day 1 & $88(10)$ & $72(19)$ & $<0.01$ \\
Day 7 & $100(4 \cdot 3)$ & $96(9)$ & n.s. \\
FEF $_{50}$ & $87(19)$ & $64(20)$ & $<0.01$ \\
Day 1 & $102(12)$ & $91(18)$ & n.s. \\
Day 7 & &
\end{tabular}

Values are mean(s.d.) percentages of preoperative results. FVC, forced vital capacity; $\mathrm{FEV}_{1}$, forced expiratory volume in $1 \mathrm{~s}$; $\mathrm{FEF}_{50}$, forced expiratory flow at 50 per cent; n.s., not significant (Student's $t$ test) was a significantly higher rate of conversion to laparotomy in group 1. The preoperative values of FVC $(P=0.001)$ and $\mathrm{FEV}_{1}(P=0.003)$ were significantly lower in group 1 than in group 2. Both groups experienced a reduction of FVC, FEV $\mathrm{F}_{1}$ and $\mathrm{FEF}_{50}$ after operation but in group 2 the fall in values was greater than in group 1 (Table 1 ).

\section{Discussion}

Between 1980 and 1989 the proportion of the Portuguese population older than 65 years increased from $11 \cdot 4$ to $13 \cdot 1$ per cent ${ }^{4}$. As the incidence of gallstones increases with age, cholecystectomy has become a common operation in older people with consequent increased risks.

One of the goals of surgical treatment of the elderly is to give the best possible quality of life and to reduce surgical stress to a minimum. This may be achieved with the laparoscopic approach, which avoids laparotomy and reduces surgical trauma.

Laparoscopic cholecystectomy has now become the 'gold standard' for treatment of symptomatic gallstone disease. This approach was attempted in all of the present patients, irrespective of age, with symptomatic gallstone disease. The incidence of single or multiple stones was similar in both groups. However, acute cholecystitis, acute pancreatitis and common duct stones, common complications of biliary lithiasis, were more frequent in the elderly as reported in other studies ${ }^{5-11}$. The mean preoperative level of alkaline phosphatase was significantly higher in the older patients $(P<0.05)$. This is probably related to the higher incidence of acute cholecystitis, acute pancreatitis and common duct stones in this age group. Operative cholangiography was performed in all patients with acute cholecystitis and acute pancreatitis. The authors use this technique in a selective manner, as do many others ${ }^{5,12-16}$.

Mortality rates for laparoscopic cholecystectomy vary from 0.04 to 0.9 per cent $t^{10,17}$ and for open cholecystectomy from 0 to 3 per cent $t^{6,18-20}$. The present series of 390 consecutive patients includes one death $(0 \cdot 3$ per cent). This is less than the reported mortality rate after open cholecystectomy in elderly patients of $3-12.7$ per cent $^{7.21-26}$.

There was no significant difference between the two groups in complications. These results may be considered favourable when compared with the reported complication rates of 18-34.6 per cent after elective open cholecystectomy in elderly patients ${ }^{7,22-26}$.

Patients in group 1 required a significantly higher number of conversions to laparotomy than those in group 2 (15 versus 4 per cent); this was also found in another report ${ }^{5}$. It reflects the chronicity of the disease resulting in a shrunken, fibrotic gallbladder and also reflects a higher incidence of acute cholecystitis and pancreatitis in this age group. Conversion to laparotomy was needed for distorted anatomy, except in one case.

The results of prospective pulmonary function testing showed that older patients have a reduced pulmonary reserve. Nevertheless, patients in group 1 experienced a smaller reduction in FVC, $\mathrm{FEV}_{1}$ and $\mathrm{FEF}_{50}$ both $24 \mathrm{~h}$ and 7 days after surgery. These findings may indicate that, from this standpoint, laparoscopic cholecystectomy is the operation of choice for older people.

No significant differences were found between the two groups in operating time and mean hospital stay after surgery. 
In conclusion, laparoscopic cholecystectomy gives good results in elderly patients and allows a comfortable postoperative course and rapid return to normal life. None of the variables analysed suggests any reason to preclude this approach and the authors believe there may be definite benefits of this treatment of symptomatic gallstones in older people.

\section{References}

1 Puri GD, Singh H. Ventilatory effects of laparoscopy under general anaesthesia. Br J Anaesth 1992; 68: 211-13.

2 Kelman GR, Swapp GH, Smith I, Benzie RJ, Gordon NLM. Cardiac output and arterial blood-gas tension during laparoscopy. Br J Anaesth 1972; 44: 1155-62.

3 Morgan GE Jr. Anesthetic considerations. In: Peters JH, DeMeester TR, eds. Minimally Invasive Surgery of the Foregut. St Louis, Missouri: Quality Medical Publishing, 1994: 14-22.

4 Instituto Nacional de Estatística: Portugal Social (1985-1990). 1992: 10-19.

5 Fried GM, Clas D, Meakins JL. Minimally invasive surgery in the elderly patient. Surg Clin North Am 1994; 74: 375-87.

6 Arnold DJ. 28621 cholecystectomies in Ohio. Results of a survey in Ohio hospitais by the Gallbladder Survey Committee, Ohio Chapter, American College of Surgeons. Am J Surg 1970; 119: 714-17.

7 Ibach JR Jr, Hume HA, Erb WH. Cholecystectomy in the aged. Surg Gynecol Obstet 1968; 126: 523-8.

8 Morrow DJ, Thompson J, Wilson SE. Acute cholecystitis in the elderly: a surgical emergency. Arch Surg 1978; 113: 1149-52.

9 Pickleman J, Gonzalez RP. The improving results of cholecystectomy. Arch Surg 1986; 121: 930-4.

10 The Southern Surgeons Club. A prospective analysis of 1518 laparoscopic cholecystectomies. $N$ Engl J Med 1991; 324: 1073-8.

11 Tucker LE, Anwar A, Hardin W, Tangedahl TN. Risk factors for cholecystectomy: analysis of 935 patients. South Med J 1983; 76: 1113-15.

12 Castro-Sousa F, Manso LC, Milheiro A. Colecistectomia celioscópica. experiência do serviço de Cirurgia III dos HUC (1991-1994). In: Monografias da Sociedade Portuguesa de Cirurgia I - Cirurgia Laparoscópica. Lisbon: Ed Sociedade Portuguesa de Cirurgia, 1995: 131-40.

13 Corder AP, Scott SD, Johnson CD. Place of routine operative cholangiography at cholecystectomy. Br J Surg 1992; 79: $945-7$.

14 Gerber A, Apt MK. The case against routine operative cholangiography. Am J Surg 1982; 143: 734-6.

15 Scott-Coombes D, Thomson JN. Bile duct stones and laparoscopic cholecystectomy. BMJ 1991; 303: 1281-2 (Editorial).

16 Teixeira A, Saraiva AC, Reis JR, Teixeira JA. Colecistectomia laparoscópica. Experiência de 100 casos. $O$ Médico 1992; 127(2076): 109-13.

17 Deziel DD, Millikan KW, Economou SG, Doolas A, Ko ST, Airan MC. Complications of laparoscopic cholecystectomy: a national survey of 4292 hospitals and an analysis of 77604 cases. Am J Surg 1993; 165: 9-14.

18 DenBesten L, Berci G. The current status of biliary tract surgery: an international study of 1072 consecutive patients. World J Surg 1986; 10: 116-22.

19 Ganey JB, Johnson PA Jr, Prillaman PE, McSwain GR. Cholecystectomy: clinical experience with a large series. $A m J$ Surg 1986; 151: 352-7.

20 Keller SM, Markovitz LJ, Wilder JR, Aufses AH Jr. Emergency and elective surgery in patients over age 70. Am Surg 1987; 53: 636-40.

21 Adda G, Bénichou J, Castro-Sousa F, Monod-Broca PH. Chirurgie de la lithiase biliaire après 75 ans. Étude de 106 cas. La Revue de Gériartrie 1981; 6: 425-8.

22 Harness JK, Strodel WE, Talsma SE. Symptomatic biliary tract disease in the elderly patient. Am Surg 1986; 52: 442-5.

23 Huber DF, Martin EW Jr, Cooperman M. Cholecystectomy in elderly patients. Am J Surg 1983; 146: 719-22.

24 Margiotta SJ Jr, Horvitz JR, Willis IH, Wallack MK. Cholecystectomy in the elderly. Am J Surg 1988; 156: 509-12.

25 Margiotta SJ Jr, Willis IH, Wallack MK. Cholecystectomy in the elderly. Am Surg 1988; 54: 34-9.

26 Smith N, Max MH. Gallbladder surgery in patients over 60 : is there an increased risk? South Med J 1987; 80: 472-4. 